\title{
Discapacidad visual, competencias y empleabilidad en el Perú ${ }^{1}$
}

\section{Visual disability, skills and employability in Peru}

Juan Pablo Bergamino Varillas

juanbergamino@gmail.com

El empleo es un medio de desarrollo económico y social que permite mejorar la calidad de vida de las personas e incrementar su sentimiento de pertenencia en tanto generan una contribución productiva a la sociedad. En el caso de las personas con discapacidad, el acceso al empleo suele ser limitado debido a que existen barreras educativas, económicas y culturales que impiden su participación en la vida laboral; sin embargo, estas personas cuentan con diversos tipos de competencias, propias de su condición, para poder realizar tareas productivas que les aseguren mantener un empleo estable y a largo tiempo. Es importante conocer cuáles son esas competencias y cómo, a través de la gestión de este talento, influyen directamente en la empleabilidad de este colectivo. Asimismo, es responsabilidad de la sociedad civil generar espacios de desenvolvimiento y desarrollo constante que el Estado y el mercado no siempre han atendido.

Palabras clave: discapacidad visual, competencias, gestión del talento, empleabilidad

Employment is a way of economic and social development, it leads people to improve their quality of life and increase their sense of belonging, as it allows them to generate a productive contribution to society. For people with disabilities, the access to employment is usually limited because of the educational, economic and cultural barriers that prevent the participation of this group in working life; however, they have different types of skills to perform productive tasks that ensure they can maintain a stable and long term employment. It is important to know what these skills are and how they influence the employability of this group. Also, it is responsibility of the society to generate spaces for the development of this group that the government and the market have left aside.

Keywords: visual disability, skills, talent management, employment

\footnotetext{
1. El presente artículo es resultado de la investigación conducente a la elaboración de la tesis de licenciatura: Oportunidades laborales en el sector masoterapia para personas con discapacidad visual: el caso de Ágora Perú, presentada a la Pontificia Universidad Católica del Perú en el año 2013. Para el desarrollo de dicha tesis se contó la asesoría del Dr. Levy del Aguila Marchena, a quien agradezco por sus orientaciones a lo largo de la investigación. Los hallazgos principales de dicho trabajo son expuestos a continuación.
} 


\section{Introducción}

Actualmente, las personas con discapacidad (en adelante PCD) alrededor del mundo cuentan con menores oportunidades debido a su limitada participación en la esfera económica y social, la falta de acceso a servicios, la educación, entre otros factores cuyos efectos concluyen en situaciones de pobreza y exclusión (OMS, 2011a, p. xi). En el Perú sigue existiendo precariedad económica, así como fragilidad institucional en el sector público y en la sociedad civil, lo que limita considerablemente las posibilidades del desarrollo humano sostenible en el país (PNU, 2002, p. 1). En este contexto, es importante investigar la situación de las PCD puesto que sus talentos no han sido considerados para el desarrollo del país.

Existen diversas organizaciones que se encargan de brindar capacitaciones a las PCD para que puedan insertarse al mercado laboral. En este artículo nos centraremos en una de ellas: Agora Perú. Esta capacita a través de talleres laborales y cursos técnicos en materias como la masoterapia que les permitan desarrollarse profesionalmente e insertarse en el mercado laboral. El objetivo del artículo es comprobar si la capacitación que brinda dicha organización mejora realmente la empleabilidad de las PCD visual y si esta toma en cuenta las habilidades técnicas y personales requeridas por las organizaciones más representativas del sector masoterapia.

Como se mencionó, las PCD cuentan con una limitada participación social. En respuesta a esa realidad, la Organización Mundial de la Salud (OMS) realizó un Informe mundial sobre discapacidad que proporciona datos y busca fomentar la formulación de políticas públicas y programas que mejoren la vida de las PCD. En dicho informe se menciona que:

En todo el mundo, las PCD tienen peores resultados sanitarios y académicos, una menor participación económica y unas tasas de pobreza más altas que las personas sin discapacidad (...) (OMS, 2011a, p. xi).

Por otro lado, el informe menciona que los principales obstáculos discapacitantes son las políticas y normas insuficientes, los prejuicios sociales, los servicios limitados, la poca financiación, la falta infraestructura accesible y el acceso a la información (OMS, 2011a, p. 10-12; OMS, 2011b).

Según esta información, las PCD en todo el mundo cuentan con un entorno desfavorecido. Este artículo se centrará en las PCD visual. En el caso peruano, el Censo Nacional 2017: XII de Población, VII de Vivienda y III de Comunidades Indígenas nos señala que el 10,4\% de la población total cuenta con discapacidad, lo cual representa 3051612 personas, siendo 1473583 -lo cual equivale al 48,29\% de este subtotal- la cantidad de PCD visual (Instituto Nacional de Estadística e Informática, 2018).

Es un problema del Estado que no se hayan podido resolver de manera eficiente las diversas circunstancias sociales adversas en virtud de las cuales la población se siente desprotegida y excluida por falta de intervención estatal y como resultado de la cultura de exclusión existente en el país. Este es el caso de las PCD. Para minimizar el impacto en estos colectivos, algunos Gobiernos promulgaron políticas públicas y servicios 
asistenciales; sin embargo, no es suficiente para el total de la población. En este sentido, surgieron organizaciones civiles de apoyo al Estado que atienden a los sectores menos favorecidos del Perú mediante el desarrollo y fortalecimiento de sus capacidades.

\section{La discapacidad en la persona y la discapacidad visual}

En el año 2001 la OMS creó la Clasificación Internacional del Funcionamiento, de la Discapacidad y de la Salud, conocida como CIF, que complementaba a la Clasificación Internacional de Deficiencias, Discapacidades y Minusvalías (CIDDM), para brindar un lenguaje estandarizado y un marco conceptual para la descripción de la salud y los estados relacionados con la salud de cara a la nueva realidad social del siglo XXI. La CIF organiza la información en dos partes: funcionamiento y discapacidad, cuyos componentes son las funciones de los sistemas corporales ${ }^{2}$ y las actividades y participación —que denotan aspectos del funcionamiento desde una perspectiva individual y social— (Minguijón, 2005, p. 37); y, factores contextuales, divididos en ambientales — que constituyen el ambiente físico, social y actitudinal_ y personales — correspondiente al estilo de vida y características particulares de cada persona- (Minguijón, 2005, p. 40; OMS, 2001, p. 11).

La CIF define a la discapacidad como un término que abarca tres puntos:

- Deficiencias corporales: son problemas que afectan una estructura o función corporal a través de una alteración en la estructura anatómica de una persona, la cual puede generarse por nacimiento o ser provocada por algún accidente (Vaz \& Cano, 2002)

- Limitaciones de la actividad: son resultado de las deficiencias corporales y representan dificultades para ejecutar acciones por sí mismos, sin ayuda de alguna persona o tecnología (Bernal, 2012).

En la tabla 1 se puede apreciar cómo impacta cada componente de la CIF en las PCD de acuerdo al tipo de discapacidad.

Tabla 1. Relación causal entre deficiencia, limitación y restricción

\begin{tabular}{c|c|c} 
deficiencia & limitación de la actividad & restricción en la participación \\
\hline Visual & Ver & Orientación \\
\hline Motora & Moverse, destreza manual & Independencia física \\
\hline Auditiva & Hablar, escuchar & Interacción social
\end{tabular}

Fuente: adaptado de Bernal (2012).

2. Las funciones corporales hacen referencia a las funciones fisiológicas de los sistemas corporales, incluyendo las funciones psicológicas. El cuerpo se refiere al organismo humano como un todo, incluyendo al cerebro; por esta razón, las funciones psicológicas se encuentran dentro de los sistemas corporales. Por otro lado, las estructuras corporales son las partes anatómicas del cuerpo, tales como los órganos, las extremidades y sus componentes (Minguijón, 2005, p. 38). 
Por otro lado, tomando en cuenta el gráfico 1, el funcionamiento y la discapacidad ${ }^{3}$ se entienden como una interacción entre la condición de salud (enfermedades, trastornos, lesiones) y los factores contextuales; sin embargo, no siempre estas interacciones constituyen una relación recíproca (OMS, 2001, p. 30). Muchas veces, las intervenciones de un elemento pueden modificar uno o más de los otros elementos. Una persona puede contar con ciertas deficiencias, pero no tener limitaciones; por ejemplo, una desfiguración como consecuencia de la lepra puede no tener efecto en la capacidad de una persona (OMS, 2001, p. 31).

\section{Gráfico 1. Interacción entre los componentes de la CIF}

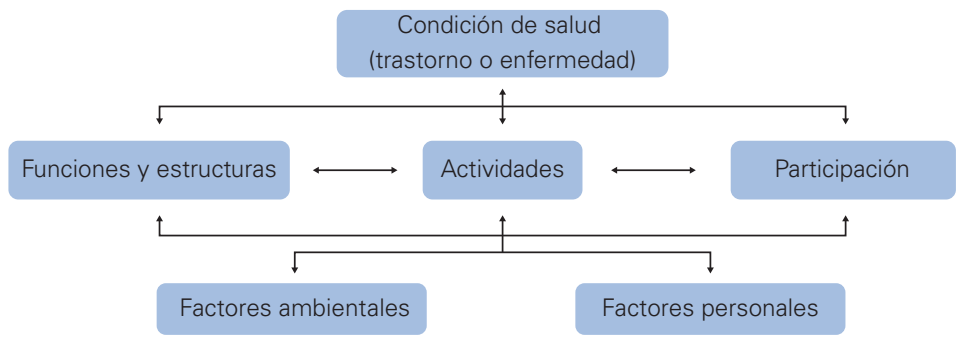

Fuente: OMS (2001).

En este sentido, se define a la discapacidad como el estado de salud de una persona en el que, debido a problemas en las funciones corporales, se genera una limitación en su accionar y, a su vez, se restringe su participación social, lo cual se encuentra relacionado a factores ambientales y personales (Minguijón, 2005, p. 41); es decir, en la interacción entre las características propias de un individuo con discapacidad y las de la sociedad estas no se complementan, por lo cual se genera una limitación y obstáculos para poder participar en la sociedad de manera plena.

\subsection{Tipos de discapacidad}

Los tipos de discapacidad se dividen en tres: física, sensorial y mental. En la primera, la persona que la padece no tiene control voluntario de su aparato muscular, así como ninguna sensibilidad en alguna o varias partes del cuerpo. Por otro lado, la discapacidad sensorial se refiere a una alteración del funcionamiento en el área del cerebro que controla sentidos como la vista y el oído, así como a quienes presentan problemas de comunicación y lenguaje. Así, la discapacidad visual equivale tanto a la pérdida total de la capacidad de ver como a una debilidad visual en ambos ojos (Gómez, 2005, p. 17). Finalmente, la discapacidad mental es la limitación en la capacidad de aprendizaje de nuevas habilidades —incluso básicaso la presencia de trastornos de conciencia y comportamiento, tanto en las actividades elementales de la vida como en su relación en sociedad (Gómez, 2005, p. 18).

Víctor Vargas Chávarri, coordinador de la Delegación Nacional del Perú ante la Unión Latinoamericana de ciegos (ULAC) y director de la ONG Sociedad y Discapacidad, indica que el término correcto es «persona en situación de discapacidad», puesto que

3. El funcionamiento y la discapacidad hacen referencia al déficit en una función o estructura corporal, a las limitaciones en la actividad y a las restricciones de la participación. 
es el resultado de la relación de una persona con sus características biopsicosociales y el entorno externo en el cual se desenvuelve (Bergamino, 2013). En este sentido, las PCD son consideradas un "grupo en situación de vulnerabilidad" debido a que, en base a sus condiciones sociales, económicas, culturales y psicológicas, se encuentran en condición de riesgo y privadas del pleno goce de sus derechos fundamentales (Secretaría de Derechos Humanos del Ministerio de Justicia y Derechos Humanos de la Nación, 2011, p. 11).

\subsection{Modelos de discapacidad}

Desde el punto de vista histórico, destacan tres modelos de comprensión y acercamiento hacia el mundo de la discapacidad que han generado un amplio impacto en sus respectivos contextos sociales. A continuación, se describe la clasificación que la doctrina ha realizado respecto a los distintos modelos de tratamiento de la discapacidad que han existido hasta llegar al modelo social, el cual ha sido tomado como base principal por la Convención Internacional sobre los Derechos de las Personas con Discapacidad y fue legitimado por la comunidad internacional.

En primera instancia, en la Antigüedad grecorromana y en la Edad Media primaba el modelo de prescindencia, el cual consideraba que la discapacidad tenía su origen en dos ejes: una justificación religiosa y la consideración de que la PCD es una carga que no aporta a la comunidad (González, 2010, p. 14). Tanto la sociedad griega como la romana buscaron medidas para prescindir de estas personas y crearon políticas eugenésicas sobre la base de motivos religiosos y políticos que consideraban como inútil el desarrollo y crecimiento de niños con discapacidad, optando por el infanticidio (Gonzáles, 2010, p. 14).

Por otro lado, en la Edad Media la subestimación de las PCD significó la exclusión y la marginación. En el mundo medieval occidental primaba la religión cristiana, razón por la que ya no se aplicaba el infanticidio; sin embargo, muchos niños morían como consecuencia de omisiones, ya sea por falta de interés, recursos o por la invocación de la fe como único medio de salvación (Arnau, 2008, p. 67). Esta sociedad, basada en pequeños productores, generaba una actitud de menosprecio y marginación a las PCD pues estas no participaban en la actividad laboral, por lo cual solo les quedaba apelar a la caridad o ejercer la mendicidad como único sustento (Palacios, 2008, p. 56).

A inicios del siglo XX este modelo inició una etapa de transformación hacia el denominado modelo rehabilitador o médico. Si bien es cierto que la orientación inicial hacia el modelo rehabilitador tuvo que ver con los accidentados laborales ${ }^{4}$, las causas que consolidan la transformación a dicho modelo son la Primera y la Segunda Guerra Mundial en tanto muchos hombres heridos resultaron afectados de por vida. A ellos se les denominó "mutilados de guerra» para diferenciarlos de los discapacitados por accidentes laborales. Por esa razón, los Estados se vieron obligados a compensar a los mutilados a través de servicios sociales establecidos por políticas legislativas (González,

4. En 1884 Bismarck promulgó en Alemania la primera ley de accidentes de trabajo, que fue imitada por casi todos los países occidentales. Por otro lado, en 1887, en España, se creó el Asilo de Inválidos para el Trabajo. Posteriormente, en 1900, se publicaría la ley de accidentes de trabajo, la cual sería la primera ley española de protección a los inválidos del trabajo, en la que se incluía el seguro voluntario y la definición de accidente de trabajo. De manera similar, en 1903 apareció el Reglamento para la declaración de incapacidades por accidentes laborales (Augado, 1995, p. 151). 
2010, p. 15). Así nace el movimiento rehabilitador, el cual se centró en los rasgos médicos de las personas y situó el problema en las deficiencias y la dificultad para realizar tareas cotidianas y profesionales, teniendo como objetivo la recuperación físicosomática y funcional (Augado, 1995, p. 182).

Se abrió la posibilidad de un mejoramiento de la calidad de vida de las personas afectadas, así como medios de prevención, tratamientos y la utilización de servicios de asistencia social, los cuales eran brindados por instituciones especializadas. Las respuestas sociales hacia las PCD se basaban en una "actitud paternalista», de manera que la asistencia social pasó a ser el principal medio de manutención y subsistencia. En este contexto aparece la modalidad de "empleo protegido» como medio de inserción laboral. Este se pensó como una solución temporal para que las PCD pudieran desarrollar sus habilidades y luego conseguir un empleo en otra organización; sin embargo, los empleadores consideraban que no eran lo suficientemente competentes debido al tipo de empleo (Palacios, 2008, p. 87), razón por la cual se convirtió en una medida asistencialista. A pesar del cambio de modelo, la situación de las PCD continuó siendo desfavorecida.

Finalmente, desde finales de los años sesenta, en Estados Unidos e Inglaterra empieza a surgir el denominado modelo social de la discapacidad o de derechos humanos, el cual rechaza que las causas de la discapacidad sean religiosas o fisiológicas, y más bien considera que el origen responde a obstáculos resultantes de factores sociales (Arnau, 2008, p. 68). Este modelo se inspiró y tomó sus bases en los movimientos civiles de los negros, las mujeres y otras minorías para dar paso al movimiento por los derechos humanos y civiles de las PCD (Del Aguila, 2007, p. 36).

Estas experiencias dieron impulso a acciones individuales de PCD como Ed Roberts, estudiante con discapacidad motora de la Universidad de California, y Paul Hunt, joven con distrofia muscular en Inglaterra, quienes no podían acceder a servicios básicos como la educación a causa de las barreras sociales y culturales. Ellos lucharon y reclamaron servicios que les eran propios por derecho (Palacios, 2008, p. 114). Estas iniciativas buscaban: a) eliminar las barreras sociales; b) que ningún aspecto, como los ingresos o la movilidad en las instituciones, sean tratados de forma aislada; c) que las PCD, con ayuda de la población, asuman el control de sus propias vidas; y, finalmente, d) que las personas que tratan de ayudar, como profesionales y expertos, se encuentren comprometidos con la promoción del control propio de las personas (UPIAS, 1976).

Este nuevo modelo se centra en la dignidad intrínseca del ser humano y sienta sus bases en valores intrínsecos a los derechos humanos, como la dignidad humana, la igualdad de oportunidades, la libertad personal frente al abuso del poder y la no discriminación (INADI, 2012, pp. 13-14). Asimismo, sitúa a las PCD como «sujetos de derechos" con voluntad para tomar sus propias decisiones y define a la sociedad como la principal fuente de problemas para el discapacitado. En este sentido, se entiende que la sociedad debe aceptar que la diferencia humana no es innata, sino creada por un aparato de poder que impone estas etiquetas para preservarlo (Palacios, 2008, p. 194; Quinn \& Geneger, 2002, p. 12).

El modelo social, al hacer referencia a la igualdad de oportunidades, no se refiere a que no existen diferencias entre las personas, sino que es responsabilidad de la sociedad autenticar esas diferencias y tenerlas en cuenta dentro de sus ideales. Bajo este enfoque, 
no debe permitirse que factores externos a la persona —es decir, aquellos sobre los cuales no tiene control— definan sus oportunidades (Quinn \& Geneger, 2002, p. 13).

El fin del modelo social es lograr que la sociedad respete la autonomía de las PCD, comprendiendo la diferencia. Supone eliminar las barreras arquitectónicas, socioeconómicas, legales y culturales; y solucionar temas de accesibilidad y diseño, de forma que puedan desenvolverse con igualdad de oportunidades, cambios que constituyen la ruta para disminuir su discapacidad (Arnau, 2008, p. 69). En este sentido, la frase mencionada por Jenny Morris ${ }^{5}$ tiene mucho sentido: "una incapacidad para caminar es una deficiencia, mientras que una incapacidad para entrar a un edificio debido a que la entrada consiste en una serie de escalones es una discapacidad» (Palacios, 2008, p. 103).

A continuación se presenta un resumen de los tres modelos antes mencionados.

Tabla 2. Resumen de modelos de discapacidad

\begin{tabular}{|c|c|c|c|c|}
\hline \multirow[b]{2}{*}{ modelo } & \multicolumn{4}{|c|}{ características } \\
\hline & periodo histórico & $\begin{array}{c}\text { origen de } \\
\text { discapacidad }\end{array}$ & $\begin{array}{l}\text { capacidad de } \\
\text { aporte social del } \\
\text { discapacitado }\end{array}$ & respuesta social \\
\hline $\begin{array}{l}\text { Modelo de } \\
\text { prescindencia }\end{array}$ & $\begin{array}{l}\text { Antigüedad } \\
\text { grecorromana } \\
\text { Edad Media }\end{array}$ & $\begin{array}{l}\text { Religioso: castigo } \\
\text { divino }\end{array}$ & Nula & $\begin{array}{c}\text { Exterminio, } \\
\text { marginación extrema }\end{array}$ \\
\hline $\begin{array}{l}\text { Modelo } \\
\text { rehabilitador o } \\
\text { médico }\end{array}$ & $\begin{array}{c}\text { Inicios } \\
\text { del siglo } X X\end{array}$ & $\begin{array}{l}\text { Médico: } \\
\text { enfermedad, } \\
\text { accidente }\end{array}$ & $\begin{array}{l}\text { Parcial/supeditada } \\
\text { a la rehabilitación }\end{array}$ & $\begin{array}{c}\text { Terapias, } \\
\text { asistencialismo, } \\
\text { rehabilitación }\end{array}$ \\
\hline Modelo social & $\begin{array}{l}\text { Finales de } \\
1960\end{array}$ & $\begin{array}{l}\text { Factores } \\
\text { sociales }\end{array}$ & Integral & $\begin{array}{l}\text { Búsqueda del cambio } \\
\text { social e igualdad de } \\
\text { oportunidades desde } \\
\text { la comprensión de la } \\
\text { diferencia }\end{array}$ \\
\hline
\end{tabular}

Fuente: adaptado de Palacios (2008).

\subsection{La discapacidad visual}

La discapacidad visual es la carencia, disminución o alteración de la visión, bajo la forma de pérdida parcial o total de la misma, debido a daños ocasionados en los ojos o en la parte del sistema nervioso encargada de procesar la información visual por traumatismos, enfermedades o defectos congénitos (Farías, 2010, p. 8). La función visual se clasifica en cuatro niveles: visión normal, discapacidad visual moderada, discapacidad visual grave y ceguera. La discapacidad visual moderada y grave se agrupan en lo que se conoce como baja visión, siendo el total de los casos de discapacidad visual la suma de aquellos con los casos de ceguera (Organización Mundial del Comercio, 2017).

5. Jenny Morris es una destacada feminista con discapacidad. En 1996 escribió Encuentros con desconocidas: Feminismo y discapacidad, en la cual muestra la experiencia de la discapacidad desde la perspectiva feminista considerando barreras psicosociales como la causa fundamental de la exclusión social de las mujeres con discapacidad. 
La baja visión es descrita por la OMS como una limitación de la capacidad visual que afecta a la persona en la realización de ciertas actividades propias de la vida cotidiana y que no mejora con corrección refractiva ${ }^{6}$ (Yépez, 2011, p. 8). Por otro lado, la ceguera es la pérdida total de la vista; es decir, existe una ausencia de la percepción de la luz, lo cual deriva en la incapacidad de percibir objetos. La ceguera supone la imposibilidad de leer, incluso con corrección óptica o magnificación de los textos escritos (Yépez, 2011, p. 9). Muchas veces las causas de la discapacidad visual son congénitas; sin embargo, las causas principales remiten a errores de refracción no corregidos como miopía, hipermetropía, astigmatismo, cataratas y glaucoma. En todos los casos la refracción de luz al interior del ojo hace que la imagen no se forme de manera nítida dentro de la retina, por lo cual son conocidos como defectos refractivos (Alemañy, 2003, p. 194).

En junio del 2012 la OMS reportó que en el mundo existen aproximadamente 285 millones de PCD visual, de las cuales 39 millones son ciegas y 246 millones presentan baja visión (OMS, 2012). Asimismo, el 90\% de los casos mundiales se concentra en los países en desarrollo.

Ese mismo año se realizó en el Perú la Encuesta Nacional Especializada sobre Discapacidad (ENEDIS), en la cual se tomó en cuenta el área urbana y rural de los 24 departamentos del país y la Provincia Constitucional del Callao, y contaba con el objetivo de obtener información estadística confiable acerca del tamaño de la población que cuenta con algún tipo de discapacidad a nivel nacional, así como conocer sus características sociodemográficas y económicas, y el nivel de funcionamiento personal, familiar y sociolaboral; sin embargo, en el año 2017 se realizó el Censo Nacional 2017: XII de Población, VII de Vivienda y III de Comunidades Indígenas que actualizaba la información recopilada en ENEDIS.

Según los resultados obtenidos en el Censo, el 10,4\% del total de la población peruana (3 051612 personas) presenta algún tipo de discapacidad, siendo 57\% mujeres, aproximadamente. La discapacidad se presenta en mayor medida en personas mayores de 60 años, que constituyen alrededor del 40\%, y luego en las personas cuyas edades se encuentran entre los 30 y 59 años, con un 35\%. El 81.5\% de las PCD encuestadas cuentan con un tipo de limitación, mientras que, la diferencia, reúne dos o más limitaciones. De las limitaciones presentadas, la incidencia más alta se da en la limitación visual con un 48,3\%, seguida por la limitación motora con $15,1 \%$, la auditiva con $7,6 \%$, del aprendizaje con 4,2\%, la de relacionamiento con 3,2\%, y, finalmente, la de comunicación con 3,1\%.

Con respecto a las personas con limitaciones visuales, el gráfico 2 presenta los departamentos en los cuales se encuentran distribuidos según el Censo. Entre los más importantes encontramos que el 38,29\% residen en Lima, seguido, en menor medida, de los departamentos de Piura con 5,62\%, La Libertad con 5,14\%, Arequipa con 4,88\%, Lambayeque con $4,16 \%$, mientras que los demás departamentos no superan el $4 \%$.

6. La corrección refractiva es la modificación de la anatomía ocular mediante una cirugía que elimina los defectos de la miopía, la hipermetropía y el astigmatismo para evitar la utilización de lentes (Moreno, 2010, p. 901). 


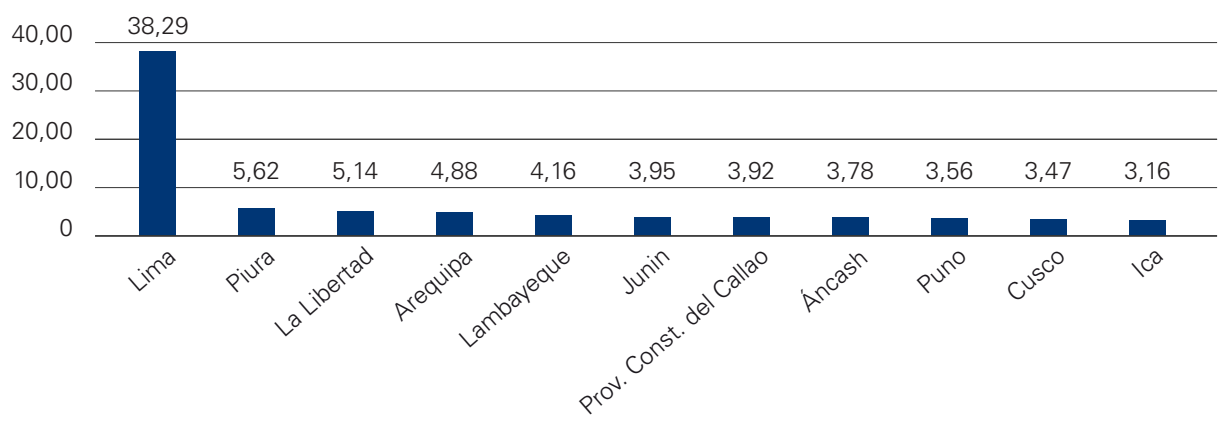

Fuente: INEI (2018).

Si bien es cierto que el Censo 2017 actualizó la cantidad de PCD e incluyó preguntas acerca de los tipos de discapacidad y ubicación geográfica, no hizo hincapié en los tipos de dificultad que presentan las PCD visual ni el grado de discapacidad que cuentan, lo cual sí se desarrolló en ENEDIS, siendo, en su momento, el 74,6\% de PCD visual quienes contaban con un nivel de discapacidad ligera y moderada, mientras que el resto la identificaba como grave y completa (INEI, 2014). Se trata de una población que ha podido desarrollar otras funciones que le permiten contrarrestar esta falencia, como el desarrollo del tacto, oído, gusto y olfato para identificar objetos, lugares y situaciones y desenvolverse de la mejor manera posible (Valdéz, 2010).

\section{La empleabilidad de las personas con discapacidad}

Luego de haber mostrado las nociones de discapacidad, los modelos de interpretación y la discapacidad visual, se presentará la relación existente entre empleo y discapacidad para conocer el vínculo entre los discapacitados visuales y su inserción en el mercado laboral desde un marco de referencia global.

\subsection{Empleo y discapacidad}

En la actualidad, el tema del empleo genera preocupación alrededor del mundo para todas aquellas personas que buscan dar sustento a sus familias. Según estadísticas del Banco Mundial, 200 millones de personas en el mundo se encuentran desempleadas, siendo el 75\% de ellas menores a 25 años (Banco Mundial, 2012, p. vii).

Para poder desarrollarse económica y socialmente las personas deben contar con un empleo que les permita alcanzar un estándar de vida saludable, lo cual aportará a la productividad y al desarrollo del país. El Banco Mundial menciona que el empleo es la base para impulsar la prosperidad y el desarrollo económico y social, y ofrece los medios que permiten escapar de la pobreza e incrementar el nivel de vida, así como la inclusión y cohesión social de los sectores menos favorecidos (Banco Mundial, 2012, p. 2; OIT, 2013, p. 1)

Asimismo, según el Informe sobre el Desarrollo Mundial 2013 (Banco Mundial, 2012), el empleo no debe abordarse solamente desde los ingresos y beneficios que 
se brinda a los trabajadores, sino también desde los productos que genera y por cómo determina la forma en que las personas se relacionan con la sociedad, siendo así un factor que transforma y mejora los niveles de vida, productividad y fomenta la cohesión social (Banco Mundial, 2012, p. 8).

\section{Gráfico 3. Empleo como factor transformador}

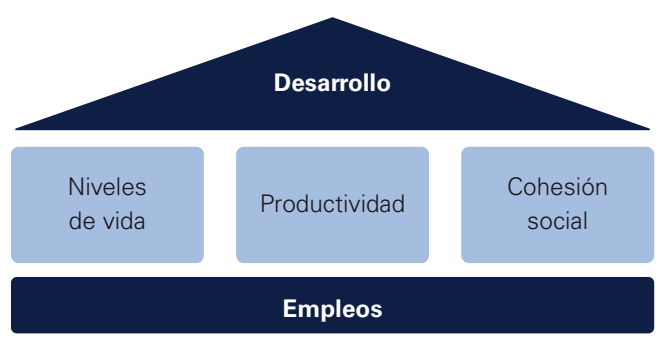

Fuente: Banco Mundial (2012).

No solo el empleo cuenta con un carácter transformador, también es importante mencionar que contar con un trabajo seguro, estable y bien remunerado es un factor clave para la autoestima de las personas y reafirma su sentido de pertenencia a una comunidad en tanto son productivos (OIT, 2013, p. 1).

En el caso de las PCD, el acceso al empleo suele ser mucho más difícil por temas que abarcan desde la falta de educación hasta los prejuicios y la marginación existentes (OIT, 2010, p. 1). Frente a este contexto de exclusión y pobreza, el trabajo es un método efectivo para romper la cadena de marginación y brindar los medios necesarios para lograr una vida plena.

En este sentido, sobre el contexto peruano, Maldonado (2006, p. 12) comenta que el tema laboral para las PCD es muy crítico pues se relaciona con áreas que no siempre trabajan de la mano: salud y educación. Sin ayudas compensatorias - como sillas de ruedas, sistema braille, lenguaje de señas, entre otros-, terapias de rehabilitación, material educativo adecuado, formación y capacitación para el trabajo la persona no se encuentra preparada para insertarse laboralmente en igualdad de oportunidades.

Asimismo, las estadísticas muestran que las PCD cuentan con menores tasas de empleo a nivel mundial. En el caso de Perú, la tasa de ocupación es de 23,8\% (OMS, 2011a, p. 268). En su informe mundial, la OMS menciona que en países desarrollados y en desarrollo las PCD en edad de trabajar cuentan con tasas de desempleo muy altas, lo cual repercute en una limitada participación en el mercado laboral, siendo una de las principales razones por las cuales la discapacidad conduce a la pobreza (OMS, 2011a, p. 256).

A pesar del contexto negativo, diversos organismos internacionales manifiestan que las PCD puedan realizar aportes muy valiosos a la sociedad a través del empleo. La OMS menciona que existen empleadores que todavía consideran que las PCD no se encuentran calificadas para realizar diversas actividades; sin embargo, ellas sí cuentan con las habilidades requeridas y representan una alta lealtad y una tasa de absentismo muy baja (OMS, 2011a, p. 266). Por otro lado, la OIT menciona que las PCD son una fuente de talento sin explotar puesto que cuentan con habilidades técnicas, si tienen acceso a la formación, y personales, que transfieren desde su vida cotidiana (OIT, 2010, p. 1). 
O’Reilly (2007, p. vii), expresidente de Rehabilitación Internacional y del Centro Europeo para el Desarrollo de la Formación Profesional (CEDEFOP), refuerza la idea de que las PCD pueden generar una gran contribución y aporte con su trabajo pues, cuando se les han brindado oportunidades en puestos que se adaptan a sus competencias, intereses y aptitudes, han demostrado ser competentes, evidenciando lo erróneos que son los prejuicios acerca de su capacidad de trabajar.

Al ser el sector privado el principal motor de la creación de empleos, en tanto representa el $90 \%$ de la totalidad de puestos de trabajo en el mundo, la importancia de generar conciencia en dicho sector sobre el carácter erróneo de los prejuicios en la contratación de las PCD es vital (Banco Mundial, 2012, p. viii). Frente a ello, cabe señalar que la OMS menciona que incluir a las PCD en la fuerza laboral es importante, pues permite maximizar los recursos humanos, promover la dignidad humana y favorece la cohesión social (OMS, 2011a, p. 266).

\subsection{Obstáculos para el discapacitado visual}

Existen muchos prejuicios sobre la realidad de las capacidades y habilidades de las PCD. Tal como se vio en el modelo social, existen distintos obstáculos para cada una de ellas. Como menciona Fabiana Mon (1999, p. 4), especialista en discapacitados visuales y directora del Centro de Recursos Educativos para Niños y Adolescentes con Discapacidad Visual de Buenos Aires, Argentina, existen diversas barreras que obstaculizan la integración laboral. Ella las divide en cuatro puntos: a) barreras técnicas y de capacitación, b) socioeconómicas, c) legales y d) culturales.

La primera barrera, técnica y de capacitación, hace referencia a que las PCD necesitan ayuda profesional para encontrar un puesto de trabajo. Muchas veces, aunque su capacitación sea la mejor y cuenten con una formación completa, necesitan un servicio que funcione a modo de agencia de colocación para ayudarlos a integrarse al mercado laboral (Mon, 1999, p. 4). La integración laboral de las PCD visual se realiza por "ensayo y error», o por instituciones que cuentan con conocimientos generales sobre la discapacidad, pero no con formación específica en lo laboral. Algunas veces, las PCD visual pueden llegar a recibir educación primaria, secundaria e incluso profesional; sin embargo, debido al competitivo mundo laboral, es difícil que puedan insertarse bajo sus propios medios.

Según lo que menciona Maldonado (2006, p. 9), la falta de acceso a la educación tiene su origen en diversas carencias. Una de ellas hace referencia a las barreras arquitectónicas que obstaculizan la participación de las PCD en la sociedad; es decir, a la infraestructura existente en el aparato educativo nacional y la oferta limitada de servicios. Un buen ejemplo se aprecia en la falta de material de lectura en braille para el aprendizaje de las PCD visual y la falta de señalización vial y peatonal. Sobre este punto, la OMS menciona que el ambiente en el que viven tiene un profundo efecto en la prevalencia y magnitud de la discapacidad. Así, si bien las catástrofes naturales modifican las deficiencias y crean barreras en el entorno físico, vemos también que, por contraste, los cambios para mejorar la accesibilidad en los medios de transporte y la infraestructura pública las reducen (OMS, 2011a, p. 42).

Por otro lado, las barreras socioeconómicas se generan principalmente por una relación causal entre discapacidad, falta de educación, falta de oportunidades laborales y 
escasez de recursos económicos. Es decir, existe un círculo vicioso que hace que el desarrollo se vea truncado. Sobre este punto, Mon (1999, p. 5) menciona que «hay situaciones donde resulta casi absurdo hablar de inserción laboral cuando no están garantizadas las condiciones mínimas de subsistencia, donde llegar a la educación básica ya resulta un privilegio». En este caso, el requisito primordial es la educación y existe una barrera que impide el acceso a la misma. En el mismo sentido, las PCD enfrentan muchas dificultades como, por ejemplo, la carencia de servicios adecuados, el acceso inequitativo a servicios básicos en salud y educación, la falta de oportunidades de empleo, y las barreras físicas y actitudinales que obstaculizan su participación en la sociedad, tal como menciona Maldonado (2006, p. 9).

Por su parte, las barreras legales hacen referencia al incipiente marco normativo que regula el entorno de las PCD en muchos países. Respecto a este punto, la OMS menciona la importancia de las leyes y normativas para revertir la discriminación en tanto forman el punto de partida para promover la inclusión al mundo laboral.

Si bien es cierto que en 1948 la Organización de las Naciones Unidas (ONU) emitió la Declaración Universal de los Derechos Humanos, en la cual expresa que se deben respetar los derechos y libertades de todas las personas sin ningún tipo de distinción, esta no logró satisfacer las necesidades de todos los colectivos debido a que, en la práctica, los grupos minoritarios sufrían discriminación, racismo y exclusión por parte de la sociedad y el Estado, y sus necesidades específicas no eran satisfechas ni atendidas, lo que se tradujo en la privación del pleno goce y ejercicio de sus derechos fundamentales. Debido a esto, fue necesario crear tratados complementarios para grupos específicos; por ejemplo, para el caso de las PCD fue necesario crear en 1974 el Tratado de los Derechos de las Personas con Retraso Mental; en 1976, los Derechos del Impedido; en 1981, el Programa de Acción para los Impedidos; y, en 1993, las Normas Uniformes sobre la Igualdad de Oportunidades para las PCD (Araya, 2013).

En el año 2008 la ONU decidió crear la Convención sobre los Derechos de las PCD, la cual era una síntesis de los distintos tratados complementarios mencionados. Esta hacía frente a los obstáculos físicos y sociales que impedían a las PCD recibir educación, conseguir empleo —incluso si se encontraban calificadas—, acceder a la información, recibir un adecuado cuidado médico y sanitario, poder desplazarse, e integrarse en la sociedad y ser aceptados (ONU, 2017). Este instrumento se ha convertido en el marco normativo global que protege y vela por los derechos y la dignidad de las PCD, y sentó sus bases en el principio de la no discriminación y participación plena.

Actualmente, el Perú se encuentra suscrito a la Convención y es responsable de enviar informes periódicos para conocer el avance en temas de discapacidad. En diciembre del 2012 se promulgó la nueva ley de PCD, Ley № 29973, la cual reemplaza a la Ley $N^{\circ} 27050$ y a las demás leyes generales que hacían referencia a PCD, y desarrolla temas de accesibilidad a puestos de trabajo e inclusión social.

Finalmente, la cuarta barrera es la cultural. Tanto en el país como en el mundo existe una cultura de exclusión a las PCD. Como menciona Mon (1999, p. 7), "la ceguera se impone, como marca, anteponiéndose a otras características personales». Esto explica que los prejuicios existentes sean tan fuertes que, incluso cuando el discapacitado visual cuenta con formación profesional, muchas organizaciones aún sobrepongan su discapacidad para evitar contratarlo. 
En conclusión, se puede afirmar que el concepto de discapacidad es complejo; sin embargo, actualmente se utiliza el concepto de "persona en situación de discapacidad", el cual expresa que la discapacidad es la relación de una persona dotada de características particulares con el entorno externo que la rodea.

\subsection{Empleabilidad y competencias laborales del discapacitado visual}

La empleabilidad se entiende como el conjunto de aptitudes y actitudes que brindan a un individuo la oportunidad de ingresar a un puesto de trabajo y permanecer en él (Campos, 2003, p. 104). Se ha decidido trabajar con este concepto puesto que incluye dos dimensiones: educación y horizonte temporal. Con respecto al primer factor, se entenderán las aptitudes como capacidades para realizar una cierta actividad y las actitudes como la voluntad de una persona para desarrollarlas; mientras que el segundo factor hace referencia a permanecer en el puesto de trabajo a largo plazo.

El concepto de competencias se encuentra estructurado en torno a las nociones de conducta, habilidad y conocimiento. Según Gordillo (2004), "las competencias son aquellos conocimientos, habilidades y actitudes que se requieren para ejercer una actividad laboral». Esta definición nos permite señalar que para realizar una actividad se debe de contar con habilidades prácticas y actitudes específicas; asimismo, es necesaria una serie de conocimientos propios de la actividad para poderla realizar de manera eficiente. Siguiendo a Tejada (2005, p. 2), el dominio de estos saberes hacen a un individuo capaz de actuar con eficacia en situaciones profesionales, contando así con el sentido de coordinación e integración de conocimientos, procedimientos y actitudes para desarrollar actividades laborales de manera eficiente.

Debido a que las PCD visual cuentan con una limitación, desarrollan otros sentidos para poder ser competentes; es decir, desarrollan otras habilidades como, por ejemplo, reconocer objetos a través del tacto, identificar fuentes de sonido a través del oído u olores que les sirven para conocer el medio y la situación en la que se encuentran a través del olfato (Valdéz, 2010).

Para comprender mejor los tipos de competencias, tomaremos la división realizada por Gordillo, quien las divide en cuatro clases: a) competencias metodológicas, b) competencias técnicas, c) competencias sociales y d) competencias individuales.

Tabla 3. Tipos de competencias

\begin{tabular}{c|c} 
tipo de competencias & definición \\
\hline Metodológicas & $\begin{array}{c}\text { Niveles precisos de conocimientos e información requeridos para desarrollar } \\
\text { una o más tareas }\end{array}$ \\
\hline Técnicas & Aplicaciones prácticas precisas para ejecutar una o más tareas \\
\hline Sociales & $\begin{array}{c}\text { Integración fluida y positiva de la persona a grupos de trabajo y su respuesta } \\
\text { a los mismos }\end{array}$ \\
\hline Individuales & Aspectos relacionados a valores como responsabilidad, puntualidad, \\
honradez, etcétera
\end{tabular}


Estas competencias se encuentran presentes, en mayor o menor medida, en las PCD visual debido a que son capaces de desarrollarlas tanto como parte de su formación, práctica y habilidades interpersonales, siempre y cuando hayan aceptado su condición y tomado conciencia de ella. Debido al contexto cambiante, es necesario que se sigan desarrollando las competencias personales y técnicas para poder ser competitivo.

\section{El papel de la sociedad civil}

En el apartado siguiente se presentará el concepto de la sociedad civil, los tipos de organizaciones y cuáles se encargan de apoyar a las PCD visual. Posteriormente, se explorará la experiencia del Proyecto Agora, organización que se encarga de la capacitación y promoción de las competencias laborales para PCD visual, indicando el tipo de capacitación que brinda para insertarlas al mercado.

\subsection{Organizaciones de la sociedad civil (OSC) y discapacidad visual en el Perú}

La definición del término sociedad civil es heterogénea debido a la gran diversidad de organizaciones que comprende. Para algunos especialistas, la sociedad civil es un resultado contingente de la construcción de la Modernidad que solo se consolida plenamente con la democracia y el estado de derecho (Olvera, 2000, p. 11). Así, la importancia de la sociedad civil recae en su funcionamiento como espacio de vigilancia de las prácticas del Estado y en su cobertura de los espacios no atendidos por el mismo; mientras que, en paralelo, funciona como espina dorsal de la sociedad y eleva con su accionar los problemas que aquejan a la esfera pública un intento por mejorar diversas situaciones (Alfie, 2004, p. 3). Asimismo, la sociedad civil no solo enfrenta las deficiencias del Estado, sino que también debe hacer frente a las falencias del mercado. En ese sentido, los actores de la sociedad económica7; es decir, «la mediación de la economía y la sociedad, son el puente que vincula la solidaridad básica de clase con los intereses mercantiles» (Olvera, 2000, p. 12).

La heterogeneidad en el concepto de sociedad civil se ve reflejada en la multiplicidad de OSC existentes. Hay diversas organizaciones que se encargan de ofrecer servicios a poblaciones desatendidas que ni el Estado ni el mercado son capaces de proveer en la dimensión y profundidad necesarias. La tipología propuesta por Olvera (2000, p. 12) define a las organizaciones civiles como entidades de promoción, desarrollo y prestación de servicios a la comunidad que tienen como objetivo la transformación y creación de agendas sociales y políticas. Estas son organizaciones formales que cuentan con un registro legal y llevan a cabo tareas específicas en proyectos de promoción del desarrollo y creación de grupos y movimientos culturales (Olvera, 2000, p. 13), por lo cual constituyen un verdadero movimiento social en la medida en que reflejan los nuevos valores morales, políticos y culturales.

En el Perú existen diversas organizaciones de la sociedad civil que se encargan de ayudar a las PCD e intentan aprovechar su talento desperdiciado. En el caso de las PCD visual se puede mencionar a la Unión Nacional de Ciegos del Perú (UNCP), el Centro de

7. La sociedad económica está conformada por los espacios de intermediación entre el mercado y la sociedad civil (Olvera, 2000, p. 12). 
Rehabilitación de Ciegos de Lima (CERCIL) y la Asociación Peruana de Ciegos Católicos, las cuales tienen por objetivo contribuir a la integración social y espiritual, así como la promoción del bienestar y la superación de las PCD a través de la evaluación y el desarrollo de sus habilidades para que puedan insertarse al mercado laboral.

Adicionalmente, está la Fundación ONCE para América Latina (FOAL), que proviene de la Organización Nacional de Ciegos Españoles (ONCE) y es una entidad no lucrativa solidaria para apoyar a PCD visual. Uno de las principales iniciativas de la Fundación ONCE es el Proyecto Agora, cuyo objetivo es incorporar a PCD visual al mercado laboral a través de asesoramiento profesional, talleres de formación, atención de necesidades básicas e inserción laboral (Fundación ONCE para América Latina, 2018, p. 14). En este sentido, se presentará el caso de esta organización para entender cómo es que se relaciona con las PCD visual y con el mercado laboral al cual pretende insertarlas laboralmente.

\subsection{El Proyecto Agora Perú: capacitación para la inclusión laboral de discapacitados visuales en el sector masoterapia}

La ONCE es una organización que tiene como propósito velar por el desarrollo de las PCD visual para que puedan desarrollarse a nivel personal y participar de la sociedad. Es el principal referente a nivel mundial pues, desde el éxito en España de los servicios que ofrecía a las PCD visual, decidió expandirse a Latinoamérica a través de la Fundación Once para la Solidaridad América Latina (FOAL). A raíz de ellos, se crea la Organización Aulas de Gestión Ocupacional para la Región América Latina, Agora Perú, que inició sus actividades en el año 2006.

Los objetivos de Agora Perú se encuentran direccionados a brindar apoyo a la mejora de la empleabilidad, la igualdad de oportunidades y la inserción laboral de personas con discapacidad visual a través de la capacitación, intermediación y orientación laboral, buscando constituirse como un organismo de consultoría.

Según el exgestor de formación de Agora Perú, Carlos Chanamé, para alcanzar esos objetivos se realizan talleres prelaborales para conocer el perfil de la persona - prestando atención a factores como el grado académico, su compromiso familiar, la personalidad, la motivación, etcétera-, así como cursos de masoterapia y teleoperaciones que se encuentran dentro de su Plan Anual de Capacitación. No obstante, a pesar de que se replica el modelo español, los resultados no son los esperados debido a los prejuicios sociales, la educación y la cultura propia de cada país (Bergamino, 2013). Es sobre la base de esos resultados que se puede proceder a verificar si la capacitación brindada responde a lo que el mercado al cual se busca insertar a las PCD requiere.

Según lo que investigado, al momento de elegir a la institución que brindará las capacitaciones, es el coordinador ejecutivo nacional quien se encarga de revisar que las propuestas se encuentren actualizadas. Así, se selecciona a la organización capacitadora en base a términos de tiempo, dinero y duración del curso. Cabe señalar, además, que no se realiza ningún estudio de mercado al temario otorgado pues se confía en que las organizaciones contratantes ya hayan realizado estudios previos (Bergamino, 2013).

En el caso específico de la masoterapia, se trabaja directamente con la Cruz Roja Peruana a nivel nacional para la implementación de cursos para 15 alumnos de seis meses 
de duración. Cada uno se encuentra dividido en módulos sobre técnicas de masajes y anatomía humana que buscan ayudar al paciente a recuperar el máximo nivel posible de funcionalidad e independencia (Cruz Roja Peruana, 2012). A continuación, la tabla 4 presenta los servicios brindados por Agora Perú.

Tabla 4. Cursos brindados por Agora Perú

\begin{tabular}{|c|c|c|c|}
\hline & talleres prelaborales & masoterapia & $\begin{array}{l}\text { teleoperaciones - } \\
\text { informática }\end{array}$ \\
\hline temas & $\begin{array}{l}\text { - Conocimiento de } \\
\text { la persona con } \\
\text { discapacidad } \\
\text { - Personalidad } \\
\text { - Rehabilitación } \\
\text { emocional: } \\
\text { comunicación, } \\
\text { desenvolvimiento } \\
\text { - Orientación hacia el } \\
\text { mercado laboral }\end{array}$ & $\begin{array}{l}\text { - Manejo de manos } \\
\text { - Técnicas de relajación } \\
\text { - Técnicas y tipos de } \\
\text { masajes. } \\
\text { - Conocimiento } \\
\text { anatómico }\end{array}$ & $\begin{array}{l}\text { - Manejo de } \\
\text { computadora } \\
\text { - Manejo de Office } \\
\text { - Manejo del software } \\
\text { JAWS } \\
\text { - Manejo de internet } \\
\text { - Conceptos básicos de } \\
\text { telefonía } \\
\text { - Manejo de software } \\
\text { Soft Phone }\end{array}$ \\
\hline cantidad & Cada dos semanas & Dos veces al año & Ocho veces al año \\
\hline duración & $\begin{array}{l}\text { Cuatro horas diarias por } \\
\text { cinco días }\end{array}$ & Seis meses & Tres meses \\
\hline $\begin{array}{l}\text { beneficiados por } \\
\text { curso }\end{array}$ & 40 personas & 40 personas & 15 personas \\
\hline ntidad capacitadora & CERCIL & Cruz Roja Peruana & INICTEL-UNI \\
\hline
\end{tabular}

Fuente: adaptado de Bergamino (2013).

Entre junio del 2006 y julio del 2017 Agora Perú ha realizado 3125 talleres prelaborales y dictado 300 cursos de formación básica ocupacional, logrando atender a población con discapacidad visual en Lima (zona sur), Arequipa y Huaraz, entre otras ciudades del Perú.

Hasta julio del 2017, Agora Perú contaba con 3223 beneficiarios inscritos a nivel nacional. Por otro lado, el número de beneficiarios orientados laboralmente mediante talleres prelaborales era de 3125, dentro de los cuales se incluye a personas que no pertenecen a la organización, pero que sí han realizado los talleres. Dicho de otra manera, Agora Perú realiza talleres a nivel nacional y convoca en provincia, ya sea por iniciativa propia de Agora o gracias al Consejo Nacional para la Integración de la Persona con Discapacidad $(\mathrm{CONADIS})^{10}$. En estas convocatorias se presenta la organización a las PCD visual y se brindan los talleres prelaborales, facilitando la opción de inscribirse libremente a Agora. También se ha capacitado en obtención de empleo a 3250 personas a nivel nacional. Sin embargo, a pesar del índice de participantes, lo más significativo de las cifras presentadas

8. Software desarrollado para las PCD que funciona como lector de pantalla.

9. Simulador de teléfono a través de la computadora.

10. EI CONADIS es un organismo público ejecutor. Está adscrito al Ministerio de la Mujer y Poblaciones Vulnerables y se especializa en formular, planificar, dirigir, coordinar, ejecutar, supervisar y evaluar las políticas nacionales en materia de discapacidad. 
por Agora Perú es que solo había logrado insertar laboralmente a 325 personas hasta julio 2017 (Portillo, comunicación personal, 26 de octubre de 2017; Agora Perú, 2017).

Según la tesis de Bergamino (2013), para conocer si la capacitación brindada por Agora Perú era la adecuada se realizaron cinco entrevistas a dueños de locales que brindan el servicio de masoterapia y contratan personal invidente. A ellos se les consultó acerca de la relación con el personal, el motivo de la contratación, el perfil profesional, las competencias personales y técnicas, la experiencia, etcétera. Los principales hallazgos acerca de la relación entre el personal invidente y el perfil profesional requerido por estas organizaciones se pueden apreciar en la tabla 5.

Tabla 5. Resultados relativos a la relación con el personal invidente y perfil profesional para el empleo

\begin{tabular}{|c|c|c|c|c|c|}
\hline categoría & blue session & $\begin{array}{l}\text { masajes en } \\
\text { braille }\end{array}$ & ojitos relax & $\begin{array}{l}\text { masajes } \\
\text { miraflores }\end{array}$ & biomasajes \\
\hline $\begin{array}{l}\text { Motivo de } \\
\text { contratación de } \\
\text { invidentes }\end{array}$ & $\begin{array}{l}\text { La fina } \\
\text { percepción } \\
\text { de sus manos } \\
\text { para identificar } \\
\text { los conjuntos } \\
\text { musculares }\end{array}$ & $\begin{array}{l}\text { Detectan los } \\
\text { problemas } \\
\text { físicos de los } \\
\text { clientes a } \\
\text { través del tacto }\end{array}$ & $\begin{array}{l}\text { Son muy } \\
\text { eficientes con } \\
\text { el sentido del } \\
\text { tacto. Dan un } \\
\text { valor añadido }\end{array}$ & $\begin{array}{l}\text { Tienen mejor } \\
\text { técnica de } \\
\text { palpación } \\
\text { y brindan } \\
\text { confianza a los } \\
\text { clientes }\end{array}$ & $\begin{array}{l}\text { Servicio } \\
\text { eficiente. } \\
\text { Cuentan con } \\
\text { una técnica } \\
\text { distinta a la de } \\
\text { las personas con } \\
\text { visión normal }\end{array}$ \\
\hline $\begin{array}{l}\text { Competencias } \\
\text { personales } \\
\text { requeridas }\end{array}$ & $\begin{array}{l}\text { Buen trato: } \\
\text { cordial y } \\
\text { empático; } \\
\text { independencia; } \\
\text { respeto }\end{array}$ & $\begin{array}{l}\text { Respeto a las } \\
\text { normas de } \\
\text { la empresa y } \\
\text { normas básicas } \\
\text { de convivencia } \\
\text { (puntualidad, } \\
\text { presencia } \\
\text { personal y } \\
\text { aseo) }\end{array}$ & $\begin{array}{l}\text { Persona } \\
\text { rehabilitada; } \\
\text { honestidad; } \\
\text { actitud positiva }\end{array}$ & $\begin{array}{l}\text { Disciplina / } \\
\text { rehabilitado; } \\
\text { responsabilidad } \\
\text { / puntualidad; } \\
\text { deseo de } \\
\text { superación }\end{array}$ & $\begin{array}{l}\text { Puntualidad; } \\
\text { compromiso } \\
\text { con el trabajo; } \\
\text { higiene personal } \\
\text { (porque se vende } \\
\text { salud) }\end{array}$ \\
\hline $\begin{array}{l}\text { Competencias } \\
\text { técnicas } \\
\text { requeridas }\end{array}$ & $\begin{array}{l}\text { Técnica de } \\
\text { masaje sueco, } \\
\text { fisioterapia, } \\
\text { masoterapia, } \\
\text { quiropraxia, } \\
\text { drenaje } \\
\text { linfático, } \\
\text { masaje japonés }\end{array}$ & $\begin{array}{l}\text { Reflexología, } \\
\text { shiatsu, masaje } \\
\text { de columna y } \\
\text { estético }\end{array}$ & $\begin{array}{l}\text { Terapia física, } \\
\text { reflexología y } \\
\text { técnicas de } \\
\text { masajes }\end{array}$ & $\begin{array}{l}\text { Técnicas } \\
\text { de roce } \\
\text { (acariciamiento), } \\
\text { fricción, } \\
\text { amasamiento } \\
\text { y presión } \\
\text { (relajante, } \\
\text { reductor). } \\
\text { Manejo de } \\
\text { idiomas }\end{array}$ & $\begin{array}{l}\text { Técnicas de } \\
\text { fricción y } \\
\text { amasamiento. } \\
\text { Relajante, } \\
\text { reflexología }\end{array}$ \\
\hline $\begin{array}{l}\text { Tiempo de } \\
\text { experiencia } \\
\text { requerido }\end{array}$ & $\begin{array}{l}\text { Un año. Hay } \\
\text { excepción } \\
\text { en caso de } \\
\text { comprobar } \\
\text { que maneja } \\
\text { la técnica } \\
\text { requerida }\end{array}$ & $\begin{array}{l}\text { Mínimo de } \\
\text { ocho meses. } \\
\text { Hay excepción } \\
\text { en caso de } \\
\text { comprobar } \\
\text { que maneja } \\
\text { la técnica } \\
\text { requerida }\end{array}$ & $\begin{array}{l}\text { No cuentan } \\
\text { con un tiempo } \\
\text { definido, pero } \\
\text { sí se requiere } \\
\text { experiencia }\end{array}$ & $\begin{array}{l}\text { Deben pasar } \\
\text { el tiempo de } \\
\text { prueba de la } \\
\text { organización: } \\
\text { un mes }\end{array}$ & $\begin{array}{l}\text { Deben aprobar } \\
\text { la prueba de } \\
\text { servicio }\end{array}$ \\
\hline
\end{tabular}

Fuente: adaptado de Bergamino (2013).

Todas las empresas entrevistadas pertenecen al sector servicios y trabajan con personal invidente y, además, cuentan con la percepción de que las PCD brindan un servicio 
más eficiente debido a que pueden identificar mejor los conjuntos musculares con sus manos y desarrollar técnicas de palpación. También señalan que es necesario que el personal haya superado las barreras mentales de su condición, acepte la realidad y tenga deseo de superación. Esto se refiere a que debe contar con competencias personales básicas tales como buen trato, respeto, rehabilitación psicológica, honestidad e higiene, entre otros, entre otros temas que se desarrollan en los talleres prelaborales que brinda Agora Perú, razón por la cual sí cumpliría con la rehabilitación personal y social de los invidentes. Asimismo, resaltaron la importancia de ciertas competencias técnicas, pues existen centros de entrenamiento que no cuentan con una especialización en lo referido a técnicas de masajes. En ese aspecto, si bien la capacitación brindada por Agora Perú era adecuada, no era lo suficientemente especializada como para que las PCD capacitadas accedan a uno de los puestos de trabajo revisados, ya que estos requerían de mayor capacitación técnica y experiencia en sistemas de masaje, lo que significaba que muy pocas personas lograban insertarse laboralmente (Bergamino, 2013). Recordemos que la capacitación brindada por Agora Peru se basa en el temario de la Cruz Roja Peruana y solo se dicta por un periodo de seis meses, mientras que para algunas organizaciones el tiempo de experiencia requerido es relativo al grado de especialización; sin embargo, es un requisito superar una prueba de servicio de acuerdo a los tipos y técnicas de masajes que utilizados cada organización.

En la tabla siguiente se muestra la diferencia entre las competencias técnicas que brinda Agora Perú, de acuerdo con el temario de la Cruz Roja, y las requeridas por las organizaciones del sector masoterapia.

Tabla 6. Diferencias entre el temario de la Cruz Roja y las competencias técnicas de las organizaciones entrevistadas

\begin{tabular}{l|l|l}
$\begin{array}{l}\text { temario de la cruz roja I } \\
\text { capacitación agora perú }\end{array}$ & $\begin{array}{l}\text { competencias técnicas } \\
\text { requeridas }\end{array}$ & \\
\hline * Técnicas de masaje sueco: & $*$ Técnicas de masaje sueco: & * Fisioterapia \\
acariciamiento, amasamiento, & acariciamiento, amasamiento, & $*$ Drenaje linfático \\
percusión y fricción & percusión y fricción & $*$ Shiatsu \\
* Reflexología & $*$ Reflexología & $*$ Quiropraxia \\
& * Fisioterapia & $*$ Masaje japonés \\
& $*$ Drenaje linfático & $*$ Masaje estético \\
& $*$ Shiatsu & \\
& $*$ Quiropraxia &
\end{tabular}

Fuente: adaptado de Bergamino (2013, p. 129).

Con esta información podemos verificar que no solo es importante una capacitación general sobre los masajes, puesto que el temario de la Cruz Roja Peruana no profundiza en mayores técnicas, sino también sobre técnicas más especializadas que se acoplen a las necesidades de las empresas del sector masoterapia, de forma que las PCD visual capacitadas por Agora Perú obtengan mejores competencias técnicas y sean más empleables. Si bien es cierto que la capacitación brindada por Agora Perú cumple con diversos puntos requeridos por las empresas, no contempla en su totalidad necesidades del mercado como la especialización en diversos tipos de masaje y el desarrollo de otras 
técnicas. Este desfase se debe a que Agora no realiza estudios de mercado en torno a cuáles son las técnicas de masaje más requeridas en el mercado laboral (Bergamino, 2013). Por ello, es necesario reforzar las técnicas brindadas por la Cruz Roja Peruana con una especialización en distintos centros certificados y dedicados al cultivo de diversas técnicas de masajes, pues así lo requiere el mercado laboral al cual apuntan las PCD capacitadas.

\section{Conclusiones}

La discapacidad es un concepto complejo que ha conocido una vasta evolución según los distintos contextos históricos desde los cuales las sociedades han afrontado sus dificultades. En este artículo se ha adoptado el modelo social de discapacidad, el cual indica que las características fisiológicas de las personas no generan una discapacidad, sino que son los obstáculos arquitectónicos, técnicos, socioeconómicos, legales y culturales de la sociedad los que les impiden a las PCD desarrollarse plenamente. Es necesario interiorizar estos obstáculos para tomar acciones en la vida cotidiana en favor de estas personas; por eso, se debe brindar las oportunidades que les permitan un pleno desarrollo, siempre respetando y adaptando el entorno a sus diferencias.

También es fundamental entender que las PCD son más vulnerables a sufrir menores tasas de empleo debido a los factores limitantes. Según el Censo Nacional 2017 existen más de 3051612 PCD en el Perú, siendo la principal discapacidad la visual, seguida por la motora. Asimismo, en el Perú, el número de PCD visual asciende a 1473583 personas (INEI, 2018) y su tasa de ocupación fue de 23,8\% (OMS, 2011a, p. 268).

Las PCD visual no solo deben tener los mismos derechos y oportunidades, sino que además están en capacidad de ser miembros activos de la sociedad pues, a pesar de su limitación, han desarrollado los sentidos del tacto, el oído, el gusto y el olfato para compensar su falencia. Asimismo, cuentan con competencias individuales y sociales que los hacen únicos para diversas actividades; sin embargo, los prejuicios existentes incrementan la discriminación por parte de la sociedad, ya que los mayores obstáculos se relacionan a la falta de consideración de su independencia y a las barreras anteriormente mencionadas.

No solo es necesario cambiar el concepto de discapacidad y brindar a las PCD mayores oportunidades laborales, también se debe entender que precisan de realizar especializaciones para insertarse de manera efectiva en el mercado laboral. Esto es consecuencia del concepto de empleabilidad, que hace referencia a las aptitudes y actitudes como un conjunto de competencias que son requisito para ingresar a un empleo. Por ello, un aspecto crucial para una cultura inclusiva es el mejoramiento de la empleabilidad de los discapacitados, abriéndoles el acceso a oportunidades laborales y a la mejora de su calidad de vida.

Por otro lado, debemos reconocer que, respuesta a la desatención del Estado y del mercado, existen organizaciones civiles que se encargan de la promoción e inserción laboral de estas personas a través de la formación y el desarrollo de sus capacidades y competencias. Para el caso de la discapacidad visual, existen entidades de apoyo como la Unión Nacional de Ciegos del Perú, CERCIL y Agora, las cuales se encargan de brindar educación, capacitación, y talleres de superación e inserción laboral. Estas organizaciones 
intentan rescatar el talento humano dejado de lado por el mercado para demostrar que las PCD son tan capaces como cualquier otra persona.

Cabe acotar que el Proyecto Agora, como iniciativa de la ONCE, tiene el objetivo de mejorar la empleabilidad, generar igualdad de oportunidades e insertar laboralmente a PCD visual mediante la capacitación y orientación laboral. A través de sus talleres prelaborales busca ayudar a las PCD visual a reconocerse como individuos capaces y motivados que hacen frente a la discriminación social. En paralelo, busca capacitar en técnicas de masajes a sus afiliados para insertarlos laboralmente en el sector masoterapia; sin embargo, la capacitación brindada no cuenta con la especialización requerida por las empresas del sector, lo cual genera que su ratio de inserción sea bajo, según la información disponible —que cubre hasta julio de 2017-.

Con respecto a los talleres prelaborales que brinda Agora, estos se realizan de acuerdo a lo requerido por las organizaciones del sector privado y público pues cumplen con rehabilitar a la persona y ayudarla a tomar conciencia de su realidad —requisitos necesarios para insertarse laboralmente-; sin embargo, no son suficientemente especializados. Sería bueno que, por ejemplo, se introduzcan talleres acerca de los derechos laborales, lo cual garantizaría las condiciones de empleo, evitando abusos y generando la posibilidad de crear emprendimientos propios.

Si bien es cierto que se ha identificado cuáles son las competencias técnicas requeridas por las organizaciones del sector masoterapia y qué es lo que necesita Agora para poder mejorar su ratio de inserción, es preciso que se realice un estudio de mercado para validar estos hallazgos en tanto nos encontramos frente a un mercado laboral cambiante y competitivo. Es primordial conocer el mercado de la masoterapia en su totalidad; es decir, conocer la cantidad de organizaciones que existen en el mercado, dónde están ubicadas, si cuentan con personal invidente y si están dispuestas a contratarlos. Esto permitiría conocer la demanda del sector y posicionarse estratégicamente. Asimismo, sería ideal formar alianzas provechosas con el sector privado para promover la inserción de sus beneficiarios.

Finalmente, según las concepciones contemporáneas de la gestión del talento humano, que sugieren fomentar el potencial del empleado a través del desarrollo de sus habilidades, el valor de las competencias personales y laborales no solo refiere a obtener beneficios para las empresas, sino también a cómo el empleado se desarrolla personalmente para alcanzar dichos resultados. En este sentido, las empresas no solo se enfocan en las competencias que residen en las habilidades y conocimientos, sino también en las asociadas con el comportamiento y las conductas (Zúñiga, 2006, p. 147). Así, «las experiencias exitosas suelen residir en la habilidad de la organización para establecer un marco de competencias que refleje su filosofía, valores y objetivos estratégicos» (Zúñiga, 2006, p. 154). 


\section{bibliografía}

Agencia Estatal de Boletín Oficial del Estado (AEBOE)

2013

Ley 13/1982, de 7 de abril, de Integración

Social de Minusválidos. Recuperado

de: <https://www.boe.es/buscar/doc.

php?id=BOE-A-1982-9983 > .

\section{Asociación Peruana de Ciegos} Católicos (APECC)

2017

Página web. Recuperado de: <https:/l www.apeccperu.org>.

\section{Aulas de Gestión Ocupacional} América Latina

Página web. Recuperado de: $<$ http:/l cercilperu.blogspot.com/2015/11/agora. $\underline{h t m l}>$.

\section{Arnau Ripollés, S.}

2008

La discapacidad dentro del enfoque de capacidades y funcionamientos de Amartya Sen. Red de Revistas Científicas de América Latina, el Caribe, España y Portugal, 10(20), 64-94.

\section{Augado, A.}

1995 Historia de las deficiencias. Madrid: Escuela Libre, Fundación ONCE. Recuperado de: <http://sid.usal.es/idocs/ F8/8.1-5051/librohistoriadelasdeficiencias. $\mathrm{pdf}>$.

\section{Alemañy, J.}

2003 Oftalmología. La Habana: Editorial Ciencias Médicas.

\section{Alfie, M.}

Globalización, Democracia y desilusión: la sociedad civil en México (1991-2004). El Cotidiano, 20(126), 128-137. Recuperado de: <http://www.elcotidianoenlinea.com. $\mathrm{mx} / \mathrm{pdf} / 12613 . \mathrm{pdf}>$.

\section{Araya, J.}

2013

A cinco años de la Convención sobre Derechos de las Personas con Discapacidad; avances y retos. Ponencia presentada en la Pontificia Universidad Católica del Perú, Lima.

\section{Banco Mundial}

Informe sobre el desarrollo mundial 2013: empleo. Washington D.C.: Banco Mundial.

\section{Bergamino, J.}

2013 Oportunidades laborales en el sector masoterapia para personas con discapacidad visual: el caso de Ágora Perú. (Tesis de licenciatura). Pontificia Universidad Católica del Perú, Lima, Perú. Recuperado de: <http://tesis.pucp.edu.pe/ repositorio/handle/123456789/5265>

\section{Bergamino, J.}

2013, Entrevista personal al licenciado Víctor

5 abril Vargas Chávarri, abogado con discapacidad visual experto en temas de personas en situación de discapacidad.

\section{Bergamino, J.}

2013, Entrevista personal a Carlos Chanamé, 22 junio exgestor de formación de Agora Perú. Bergamino, J. (2017, 26 de octubre). Entrevista personal a Darío Portillo, excoordinador ejecutivo nacional de Agora Perú.

\section{Bernal Ruiz, L.} Masoterapia. Oposiciones en fisioterapia. España. Recuperado de: <http://bernal.pro/ fisio/fisioposiciones>.

\section{Campos, G.} Implicaciones económicas del concepto de empleabilidad. México: Universidad Autónoma de Puebla. 


\section{bibliografía}

\section{Calvo, J.}

2004 Centros Especiales de Empleo: situación jurídica actual y perspectivas de futuro.

Madrid: Gezki.

Centro de Rehabilitación de Ciegos de Lima (2017). Página web. Recuperado de: $<$ http://cercilperu.blogspot.pe/2015/11/ agora.html>.

\section{Cruz Roja Peruana}

2012 Manual del curso de especialización en Técnicas de Masoterapia. Material de enseñanza no publicado. Lima: Cruz Roja Peruana.

\section{Del Aguila, L.}

2007 El concepto de discapacidad y su importancia filosófica. (Tesis profesional de licenciatura en Filosofía). Pontificia Universidad Católica del Perú, Lima, Perú.

\section{Farías, $\mathbf{R}$.}

Actividades en el trabajo grupal

musicoterapéutico en niños con discapacidad visual y déficit asociados. (Monografía para optar al Curso de Especialización de Postítulo en Terapias de Artes, Mención Musicoterapia). Escuela de Postgrado de la Universidad de Chile, Santiago, Chile). Recuperado de: <http:// repositorio.uchile.cl/tesis/uchile/2010/arfarias r/pdfAmont/ar-farias r.pdf $>$.

\section{Fundación ONCE para}

\section{América Latina}

Memorial social. España: ONCE.

Recuperado de: $\leq$ https://www.foal.es/ sites/default/files/social_memo_2017_final. $\mathrm{pdf}>$.

\section{Gómez, V.}

2005 La anomia para las personas con discapacidad. (Tesis profesional de licenciatura en Derecho). Universidad de las Américas Puebla, Puebla, México. Recuperado de: <http://catarina.udlap. mx/u_dl_a/tales/documentos/ledf/ gomez m v/capitulo2.pdf>

\section{Gonzáles Ramos, A.}

2010 Capacidad jurídica de las personas con discapacidad.México: Comisión Nacional de los Derechos Humanos.

\section{Gordillo, H.}

2004 Evaluación de competencias laborales.

Recuperado de: <http://www.gestiopolis. com/canales2/rrhh/1/evacomlab.htm $>$.

Instituto Nacional contra la Discriminación, la Xenofobia y el Racismo (INADI)

2012 Documentos temáticos INADI:

Discapacidad y no discriminación.

Buenos Aires: Instituto Nacional contra la

Discriminación, la Xenofobia y el Racismo.

Recuperado de: <https://www.educ.ar/

recursos/118737/documentos-tematicos-

discapacidad-y-no-discriminacion>

\section{Instituto Nacional de}

\section{Estadística e Informática (INEI)}

2014 Primera Encuesta Nacional sobre

Discapacidad 2012. Lima. Recuperado

de: <https://www.inei.gob.pe/media/

MenuRecursivo/publicaciones digitales/

Est/Lib1171/ENEDIS\%202012\%20-\%20

COMPLETO.pdf > . 


\section{Instituto Nacional de Estadística e Informática (INEI)}

Perú: Perfil Socio demográfico. Informe

Nacional. Censo Nacional 2017: XII

de Población, VII de Vivienda y III

de Comunidades Indígenas. Lima.

Recuperado de: <https://www.inei.gob.

pe/media/MenuRecursivo/publicaciones digitales/Est/Lib1539/index.html>

Maldonado Zambrano, S.

Trabajo y discapacidad en el Perú: mercado laboral, políticas públicas e inclusión social de las personas con discapacidad.

Lima: Comisión Especial de Estudio Sobre Discapacidad del Congreso de la República, Fondo Editorial del Congreso del Perú.

\section{Minguijón, J.}

Discapacidad y empleo. Zaragoza: IALDA

Taller de Ideas. Recuperado de: < http:// www.aragon.es/estaticos/ImportFiles/07/ docs/Areas\%20Genericas/Publicaciones/ DISCAPACIDAD EMPLEO.pdf>

Mon, F.

Discapacidad visual, rehabilitación y trabajo. Recuperado de: <https://es.scribd. com/document/261779251/Fm-Dv-

Rehabilitacion-y-Trabajo >

\section{Moreno, R.}

Cirugía refractiva: indicaciones, técnicas y resultados. Revista Médica Clínica Las Condes, 21(6), 901-910. Recuperado de: $<$ http://www. clinicalascondes.com/areaacademica/pdf/MED 21 6/5 Dr Moreno. $\underline{p d f}>$.

Organización Mundial de Comercio (OMC)

Discapacidades. Recuperado de: <http:// www.who.int/topics/disabilities/es/>.
Organización Mundial de la Salud (OMS)

Clasificación Internacional del

Funcionamiento, de la Discapacidad

y de la Salud. España: Ministerio

de Trabajo y Asuntos Sociales.

Recuperado de: <http://apps.who.int/iris/ bitstream/10665/43360/1/9241545445 spa.pdf >

\section{Organización Mundial de la}

\section{Salud (OMS)}

$2011 a$

Resumen. Informe Mundial sobre la

Discapacidad. Suiza: Organización Mundial de la Salud. Recuperado de: <http://www. who.int/disabilities/world_report/2011/en/>

\section{Organización Mundial de la} Salud (OMS)

2011b Comunicado de prensa: más de 1000 millones de personas con discapacidades deben superar a diario obstáculos importantes. Recuperado de: <http://www. who.int/mediacentre/news/releases/2011/ disabilities 20110609/es/>.

\section{Organización Mundial de la} Salud (OMS)

Ceguera y discapacidad visual. Nota descriptiva $N^{\circ}$ 282. Recuperado de: < $\underline{\mathrm{http}: / /}$ www.who.int/mediacentre/factsheets/ fs282/es/>.

\section{Organización Internacional del} Trabajo (OIT)

Discapacidad en el lugar de trabajo: prácticas de las empresas. Ginebra: Organización Internacional del Trabajo. Recuperado de: <http://www.ilo.org/public/ spanish/dialogue/actemp/downloads/ publications/working_paper_n3_sp.pdf > .

\section{Organización Internacional del Trabajo (OIT)}

La importancia del empleo y los medios de vida en la agenda para el desarrollo con posterioridad a 2015. Ginebra: Organización Internacional del Trabajo (OIT) (2016). La importancia del empleo y los medios de vida en la agenda para el desarrollo 


\section{bibliografía}

con posterioridad a 2015. Recuperado

de <http://www.ilo.org/wcmsp5/groups/

public/---dgreports/---dcomm/documents/

statement/wcms_206443.pdf >.

\section{O’Reilly, A.}

2007 El derecho al trabajo decente de las personas con discapacidades. Ginebra:

Oficina Internacional del Trabajo.

Recuperado de: <http://www.ilo.org/

wcmsp5/groups/public/@dgreports/@ dcomm/@publ/documents/publication/ wcms 091966.pdf>

\section{Organización de las Naciones Unidas (ONU)}

Declaración Universal de Derechos

Humanos. Recuperado de: <http://www. un.org/es/universal-declaration-humanrights/>.

\section{Olvera, A.}

Organizaciones de la sociedad civil: breve marco teórico. Documentos de discusión sobre el Tercer Sector. Zinacantepec: El Colegio Mexiquense. Recuperado de: $<$ http://www.cmq.edu.mx/index.php/ docman/publicaciones/documentos-dediscucion/88-dd0080206/file>

\section{Palacios, A.}

2008 El modelo social de discapacidad: orígenes, caracterización y plasmación en la convención internacional sobre los derechos de las personas con discapacidad. Madrid: Grupo Editorial CINCA.

\section{Programa de las Naciones Unidas para el Desarrollo (PNUD)}

Una perspectiva de desarrollo humano para el Perú. En Informe sobre el Desarrollo
Humano Perú 2002. Lima: Programa de la Naciones Unidas. Recuperado de: $<$ http://sinia.minam.gob.pe/documentos/ informe-desarrollo-humano-peru-2002aprovechando-las-potencialidades $>$.

\section{Quinn, G. \& T. Geneger}

Uso actual y posibilidades futuras de los instrumentos de derechos humanos de las Naciones Unidas en el contexto de la discapacidad. En Derechos humanos y discapacidad. Ginebra: Naciones Unidas. Recuperado de: < repositoriocdpd.net:8080/bitstream/ handle/123456789/614/L QuinnG DerechosHumanosDiscapacidad 2002. pdf? sequence $=1>$.

Secretaría de Derechos Humanos del Ministerio de Justicia y Derechos Humanos de la Nación

2011 Grupos en situación de vulnerabilidad y derechos humanos: políticas públicas y compromisos internacionales. Buenos Aires: Área de Publicaciones de la Secretaría de Derechos Humanos del Ministerio de Justicia y Derechos Humanos de la Nación. Recuperado de: <http://www.jus.gob.ar/media/1129151/31grupos vulnerables.pdf>

\section{Tejada, J. \& A. Navío}

2005 El desarrollo y la gestión de competencias profesionales. Revista Iberoamericana de Educación. 37(2). Recuperado de: <http:// www.rieoei.org/deloslectores/1089Tejada. pdf>. 


\section{bibliografía}

\section{Union of the Physically}

Impaired Against Segregation (UPIAS)

1997

Fundamental Principles of Disability.

Londres: Disability Alliance.

\section{Valdéz, L.}

2010 Discapacidad visual. Ecuador: Dirección Provincial de Educación de Guayas.

Recuperado de: <http://www.educar.ec/ noticias/visual.pdf>.

\section{Vaz, F. \& A. Cano}

2002 Clasificación de las deficiencias, discapacidades y minusvalías. En / Congreso virtual de derecho y discapacidad en el nuevo milenio (pp. 679-687).

Recuperado de: <https://dialnet.unirioja.es/ servlet/libro?codigo $=657005>$.

\section{Yépez, F.}

en la calidad de vida de las personas con discapacidad y su relación con el cumplimiento de la Reforma al Código de Trabajo Ecuatoriano investigado en las empresas más representativas del cantón Rumiñahui. (Tesis para obtener título de Magister en Gestión y Desarrollo Social). Universidad Católica de Loja, Quito, Ecuador. Recuperado de: <http://dspace. utpl.edu.ec/bitstream/123456789/4228/3/ $\underline{\text { UTPL Yepez Flavia 331X140.pdf>. }}$

\section{Zúñiga, F.}

2006 Competencias en la formación y en la gestión de talento humano. Anales de la Educación Común, 2(5), 1-20. Recuperado de: <http://www.upla.cl/ armonizacioncurricular/wp-content/ uploads/2016/05/Competenciasen-la-formacio \% CC \%81n-y-en-lagestio \% CC $\% 81$-de-talento.pdf >

Fecha de recepción: 30/04/2018 Fecha de aceptación: 13/08/2018 